\title{
PROCESSO HISTÓRICO DE ELABORAÇÃO DOS DOCUMENTOS CURRICULARES PARA A EDUCAÇÃO FÍSICA NA REDE PÚBLICA MUNICIPAL DE ENSINO DE CAMPO GRANDE - MS
}

\author{
Jorge Luis D'Avila \\ Universidade Federal de Mato Grosso do Sul - UFMS \\ Christiane C M Fernandes \\ Secretaria de Educação de Campo Grande - SEMED
}

\section{RESUMO}

Este artigo resulta de uma pesquisa bibliográfica e documental e tem como objetivo apresentar o processo histórico de elaboração dos documentos curriculares para a Educação Física na rede pública municipal de ensino de Campo Grande, Mato Grosso do Sul, destacando aspectos relevantes para compreender o pensamento ideológico assumido pela rede em questão. Para tanto recorremos ao método materialismo histórico dialético verificando assim, que as propostas curriculares para a Educação Física foram elaboradas para atender as exigências impostas pelo capital no que se refere a uma formação básica para o mercado de trabalho.

Palavras-chave: Documentos Curriculares; Educação Física, Rede de Ensino.

\section{HISTORICAL PROCESS OF ELABORATION OF CURRICULUM DOCUMENTS TO PHYSICAL EDUCATION IN THE PUBLIC MUNICIPAL ENVIRONMENT OF CAMPO GRANDE - MS}

\begin{abstract}
This article is a result of a bibliographic and documental research and has the goal to present the historical process of elaboration of the curriculum documents for the physical education in the public municipal environment of Campo Grande, Mato Grosso do Sul, focusing on some points that we consider relevents to understand the ideological thought taken by the public system we've talk about. Therefore, we used the as a method the dialetical historical materialism, understanding, in this way, that the curriculum proposes for the physical education were elaborated to attend the demands of the capital to the basic formation to the work market .
\end{abstract}

Keywords: Curriculum documents; physical education; environment of teaching.

\section{Introdução}

Este artigo resulta de uma pesquisa bibliográfica e documental e tem como objetivo apresentar o processo histórico de elaboração dos documentos curriculares ${ }^{1}$ para a Educação Física na rede pública municipal de ensino de Campo Grande, Mato Grosso do Sul (MS). Elegemos como objeto de estudo tais documentos, pois é o norteador do trabalho docente nas escolas da rede municipais de ensino, uma vez que delineia as práticas pedagógicas. 
Estes documentos, elaborados pelas secretarias de educação atendem às determinações da Lei de Diretrizes e Bases da Educação (LDB nº 9394/96), bem como das Diretrizes Curriculares Nacionais da Educação Básica (BRASIL, 2013) e são considerados um "[...] testemunho público e visível das racionalidades escolhidas e da retórica legitimadora das práticas escolares" (GOODSON, 2010, p. 21).

Neles estão organizados os objetivos, métodos e conteúdos que devem ser repassados aos alunos, alicerçados a um projeto político resultante de embates vinculados a um projeto social. Assim, quando nos propomos a analisar as propostas curriculares ${ }^{2}$ de uma rede de ensino devemos ter consciência que estas seguirão as determinações ideológicas do grupo político que se encontra à frente do Estado.

As propostas curriculares analisadas totalizam três. São elas: Alternativas Curriculares (CAMPO GRANDE, 1990), Sequência Didática (CAMPO GRANDE, 2000) e Diretrizes Curriculares do Ensino Fundamental $1^{a}$ a $8^{a}$ séries (CAMPO GRANDE, 2008).

A elaboração dos documentos curriculares para a Educação Física da rede pública do município de Campo Grande/MS é um processo histórico que teve início na década de 1990. Acreditamos que este estudo apresenta-se como possibilidade de auxiliar futura discussões críticas acerca das propostas curriculares escolhidas para a análise, bem como contribuir não somente com os professores da REME de Campo Grande/MS, mas com os que pertencem as demais redes de ensino do país, no que tange ao debate sobre documentos curriculares de Educação Física para o ensino fundamental.

A partir desta introdução, este artigo encontra-se estruturado em três partes sendo a primeira relacionada aos diferentes currículos de Educação Física durante os séculos XX e XXI, a segunda traz uma discussão e análise do objeto de estudo, e a última destaca os principais pontos abordados no texto.

\section{Relato histórico dos currículos de Educação Física}

Ao analisarmos o processo histórico de elaboração dos documentos curriculares para a Educação Física da Rede Municipal de Ensino (REME) de Campo Grande/MS, fazse necessário lembrar que os currículos desta disciplina, também como resultado de um processo histórico, sofreram importantes reformulações ao longo dos séculos XX e XXI, de forma a atender aos interesses políticos e/ou econômicos de determinados grupos que se encontravam no poder.

Assim, a Educação Física tem assumido diferentes objetivos, desde treinamento militar, higienista, eugenista, nacionalismo, preparação de atletas, entre outros.

Ao longo da história, a Educação Física como instituição, do mesmo modo que a Educação, representou diferentes papeis, adquiriu diferentes significados, conforme o momento histórico, e tem sido utilizada, muitas vezes, como instrumento do poder, para veiculação de ideologias dominantes e preservação do status quo (GONÇALVES, 1994, p.135, grifo da autora).

Nos anos1930, a perspectiva dominante da Educação Física era a higienista. Visava a desenvolver hábitos de higiene e saúde por meio dos exercícios físicos, a fim de melhorar a qualidade de vida da população (BRASIL, 1998). Sob a influência militar e médica, por exemplo, o currículo incluía, como objetivos, formar corpos fortes e saudáveis, com finalidade de atuação nas guerras, além de fortalecer a saúde e a higiene do povo. 
Conforme Darido e Rangel (2005), tanto a concepção higienista quanto a militarista consideravam a educação física como uma disciplina que não necessitava de fundamentação teórica, pois era tida como essencialmente prática.

A partir dos anos $1980^{3}$ período caracterizado como a crise da Educação Física, por influência das ciências sociais e humanas na área, novas concepções de currículo surgiram, em contraposição às concepções predominantes até então, isto é, a biologicista, que tinha como função principal a promoção da saúde, e a esportivista, em que o esporte se tornou prática hegemônica nas aulas de educação física, em virtude da sua relevância política e econômica à época da ditadura militar no Brasil.

Com o fim do período ditatorial, surgiram concepções críticas da área, em contraposição ao status quo dominante, entre elas, a Psicomotricidade idealizada por Le Boulch, trazendo a discussão sobre a educação pelo movimento e o desenvolvimento das estruturas psicomotoras de base; a Desenvolvimentista, por Go Tani, alicerçada na aprendizagem motora; e a Construtivista, pautada nos estudos do epistemólogo suíço Jean Piaget e divulgada a partir dos estudos de João Batista Freire, sugerindo uma redescoberta do corpo, além de enfatizar a infância, a individualidade da criança, o estímulo à criatividade e à liberdade individual, levando-se em conta a interação do indivíduo com o mundo (DAOLIO, 1998).

Além dessas concepções, surgiram, ainda nos anos 1980, as concepções CríticoSuperadora e Crítico-Emancipatória, caracterizadas, como o próprio nome revela, como críticas ou progressistas. Por meio da prática pedagógica, tem-se como objetivo formar um aluno capaz de entender a realidade em que está inserido.

Darido (2001) assinala que ambas as concepções

[...] passaram a questionar o caráter alienante da Educação Física na escola, propondo um modelo de superação das contradições e injustiças sociais. Assim, uma educação física crítica estaria atrelada as transformações sociais, econômicas e políticas tendo em vista a superação das desigualdades sociais (DARIDO, 2001, p.120).

A concepção Crítico-Superadora, de base marxista, ancorada na Pedagogia Histórico-Crítica (SAVIANI, 2011), propõe um ensino que atenda aos interesses da classe trabalhadora. Foi amplamente divulgada pela obra Metodologia do ensino da educação física (SOARES, et al., 1992), conhecida também como coletivo de autores.

A obra em questão discute a necessidade de superação da sociedade capitalista, entendendo que o currículo, ao invés de se voltar para a prática na educação física escolar, deve proporcionar aos alunos, como objeto de ensino da área, os temas da cultura corporal $^{5}$ : jogos, esporte, ginástica, lutas e danças, com vistas a uma análise crítica dessas práticas corporais.

Para Soares et al.(1992, p. 39), é essencial que o aluno perceba que “[...] o homem não nasceu pulando, jogando etc. Todas essas atividades corporais foram construídas em determinadas épocas históricas, como respostas a determinados estímulos, desafios ou necessidades humanas".

Portanto, sob a ótica Crítico-Superadora, a Educação Física tem como objetivo fazer o educando experimentar diferentes manifestações corporais, com a finalidade de entender como estão presentes na sociedade, bem como analisar os motivos pelos quais determinadas manifestações são privilegiadas socialmente, em detrimento de outras. 
Por outro lado, a concepção Crítico-Emancipatória, tem como principal expoente Elenor Kunz (2003) que se sustenta na filosofia fenomenológica é reconhecido também como autor que se vale da teoria da Escola de Frankfurt. Seu foco é o ensino do esporte por meio da transformação didático-pedagógica, cujo objetivo é contribuir para a reflexão crítica e emancipatória dos alunos.

Nessa linha de pensamento, a visão Crítico-Emancipatória discute o esporte pedagogicamente e propicia uma prática emancipatória, levando o aluno a pensar e agir de forma que desenvolva uma consciência crítica, a autorreflexão, tentando sobreviver em uma sociedade excludente, desenvolvendo processos autônomos e, com isso, contribuindo para a sua emancipação.

\section{Os documentos curriculares para a Educação Física da Rede Pública Municipal de Ensino de Campo Grande/MS}

Ao abordamos os documentos curriculares para a Educação Física, elaborados pela Secretaria Municipal de Educação (SEMED) de Campo Grande/MS, faz-se necessário pontuar que, de acordo com a LDB n ${ }^{\circ}$ 9394/96, que regulamenta a educação brasileira, e da lei complementar $\mathrm{n}^{\circ} 10.328 / 01$ (BRASIL, 2001), a disciplina passou a ser considerada componente curricular obrigatório da educação básica, deixando assim, de ser apenas uma atividade à parte do processo educacional.

Posteriormente, a Lei $n^{\circ} 10.793$ (BRASIL, 2003), ao dar uma nova redação ao art. $26 \S 3$ da LDB em questão, estabeleceu que a Educação Física deveria, também, ser integrada à proposta pedagógica da escola.Assim, tornou-se "[...] responsável pela apreensão (no sentido de constatação, demonstração, compreensão e explicação) de uma dimensão da realidade social, na qual o aluno está inserido" (CASTELLANI FILHO, 1998, p. 53-54).

A Educação Física como componente curricular integra o processo de escolarização, e, ao analisar os documentos eleitos para este estudo, compreenderemos que tipo de educação está sendo oferecido para os alunos do Ensino Fundamental na Rede de Ensino do município de Campo Grande/MS.

O primeiro esforço, para a elaboração de uma proposta curricular que norteasse o trabalho docente nas escolas municipais foi realizado no início da década de 1990 quando a SEMED de Campo Grande, Mato Grosso do Sul (MS) elaborou o "Plano Setorial de Educação".

Importa citar que neste momento histórico, as escolas da Rede de Ensino anteriormente mencionada, não tinham uma proposta de trabalho sistematizado para a Educação Física. Cada unidade escolar elaborava sua proposta pedagógica. Esse fato caracterizava a falta de afinidade pedagógica entre as escolas municipais.

Entendemos a necessidade de conhecer o percurso histórico de elaboração das propostas curriculares, objetos deste estudo, pois, permite que o professor de Educação Física seja direcionado a entender como as determinações econômicas, sociais e políticas influenciam o seu fazer pedagógico. Esse conhecimento pode acarretar em mudanças na prática docente, visto que elas não se limitam ao domínio metodológico e ao espaço escolar.

Nesse ínterim, vale destacar, que a elaboração dos documentos curriculares publicados pela SEMED de Campo Grande/MS seguiram as determinações impostas na Conferência Mundial de Educação para Todos, realizada em Jomtien - Tailândia, em 
março de 1990, da qual resultou, no Brasil, o Plano Decenal de Educação para Todos (1993-2003). Esse encontro foi organizado pela: Organização das Nações Unidas para a Educação, a Ciência e a Cultura (UNESCO), pelo Fundo das Nações Unidas para a Infância (UNICEF), pelo Programa das Nações Unidas para o Desenvolvimento (PNUD) e pelo Banco Mundial (BM). Teve com resultado o encaminhamento que os chamados países do terceiro mundo deveriam dar para suas políticas educacionais.

Assim, para que as metas impostas por tais organismos fossem alcançadas a educação brasileira deveria se sustentar em quatro pilares: aprender a conhecer, aprender a fazer, aprender a viver juntos (viver com os outros) e aprender a ser. Tais metas estabelecem vínculos diretos com a preparação dos alunos para se tornarem empregáveis.

Seguindo as regras impostas pela ordem econômica mundial, orientada pelo Banco Mundial (BM), Banco Internacional para a Reconstrução e Desenvolvimento (BIRD) e Fundo Monetário Internacional (FMI), no início da década de 1990 a SEMED mobiliza um grupo de técnicos de diferentes áreas curriculares para compor o "Laboratório de Currículo".

O resultado do trabalho desse grupo foi à publicação do documento intitulado Alternativas Curriculares (1990). O Referido documento se fundamentava nas concepções do pensamento construtivista e contemplava as seguintes áreas do conhecimento: Língua Portuguesa, Matemática, História, Geografia, Ciências e Educação Artística ${ }^{6}$.

Sobre as Alternativas Curriculares (1990) apontamos: ausência do componente curricular Educação Física e a não mobilização dos professores por parte da SEMED, para a construção coletiva do documento.

Como anteriormente exposto, a Educação Física se tornou componente curricular somente com a LDB n ${ }^{\circ}$ 9394/96, o que pode justificar sua ausência na primeira proposta curricular elaborada na SEMED.

O que sustentou a organização curricular na rede de ensino público no município de Campo Grande foi às determinações econômicas exigidas pelas políticas neoliberais. As múltiplas determinações econômicas que regulam as políticas sociais, dentre elas, a educação, são explicadas por Zibas (2005) da seguinte forma:

\footnotetext{
As reformas educacionais em curso e o atual processo de transformação do Estado, que decorre da nova forma de acumulação do capital. Essa nova forma de acumulação utiliza mecanismos tais como: ampliação e maior velocidade da renovação da base científica e tecnológica da produção, a abertura total de mercados dos países periféricos concomitante à manutenção de diversos mecanismos protecionistas nos mercados do Primeiro Mundo, o livre e instantâneo fluxo financeiro internacional, a intensificação do trabalho e o desemprego estrutural, a restrição a direitos trabalhistas historicamente conquistados, a diminuição da renda dos salários. (ZIBAS, 2005, p. 03)
}

Essa organização de produção exige um novo tipo de educação, na qual, segundo o pensamento liberal, o ensino público é o responsável por formar um indivíduo livre das amarras do ensino, a responsabilidade do seu êxito ou fracasso depende de que forma ele se qualificará adquirindo novas competências para "[...] responder adequadamente às demandas aceleradas postas pela atual forma de acumulação do capital" (NORONHA, 2002, p. 71).

Além de oferecer uma formação que corresponda às exigências da sociedade capitalista, as políticas neoliberais entendem que o Estado, deve minimizar seus gastos, 
principalmente nas áreas sociais (OLIVEIRA, 1988). Desse modo, a Prefeitura de Campo Grande/MS organizou seu sistema para atender às novas necessidades da acumulação do capital, permitindo assim, a inserção de trabalhadores de forma competitiva na nova dinâmica mundial. A relação Capital/Estado decorre do fato de que:

Sendo o Estado capitalista um Estado de classes, tende a organizar a escola em todos os níveis e modalidades de ensino, conforme a concepção de mundo da classe dominante e dirigente, embora, contraditoriamente, dependendo do grau de difusão da pedagogia da contra-hegemonia na sociedade civil, a mesma escola esteja permeável à influência de outros projetos político-pedagógicos. A escola, no capitalismo monopolista, sob a hegemonia burguesa, vem-se estruturando com vistas a formar, tanto em sentido amplo como em sentido estrito, um indivíduo, que apresenta como características principais o aumento da capacitação técnica necessária à reprodução ampliada das relações capitalistas de produção e uma nova capacitação dirigente, com vistas a humanizar as relações de exploração e de dominação burguesas, enquanto possibilidades históricas concretas (NEVES; SANT'ANNA, 2005, p. 29).

Nesta perspectiva, a organização do currículo da REME, se explica pela possibilidade de formar um trabalhador capaz de atender as múltiplas transformações que os meios de produção exigem em sua fase monopólica, a instrução educacional é vista como condição indispensável para o desenvolvimento econômico do país; aliado a isto, a melhoria das condições sociais. Porém, para Pochmann (2001) o cenário para o mundo do trabalho reflete nas mutações marcadas pela insegurança e competição. $\mathrm{O}$ autor pondera que:

[...] conhecimentos científicos e tecnológicos estariam associados às exigências empresariais de contratação de empregados com polivalência multifuncional e maior capacidade motivadora e habilidades laborais no exercício do trabalho. Esses requisitos profissionais, indispensáveis ao ingresso e à permanência no mercado de trabalho em transformação, seriam passíveis de atendimentos somente por meio de um maior nível educacional dos trabalhadores. Ao mesmo tempo, a formação e o constante treinamento profissional se transformariam em uma das poucas alternativas passíveis de ação do Estado para conter o avanço do desemprego (POCHMANN, 2001, p.52).

Zibas (1999) ressalta que, se por um lado a expansão do ensino básico democratizou o acesso à escola, contraditoriamente seu currículo é composto por conteúdos enciclopédicos e descontextualizados, sociabilizados por meio de uma metodologia tradicionalista, acrítica, que não tem ensinado a leitura da sociabilidade contemporânea à juventude, o que impossibilita a compreensão histórica das relações estruturantes do mundo econômico e social, e em decorrência a ausência de percepção de que a sociedade é passível de transformação.

Nesse mesmo viés no ano de 2000 a SEMED publica o documento Sequência Didática organizada em único volume, dividida por áreas de conhecimento e elaborada 
pelos técnicos da equipe de Educação Física que trabalhavam na secretaria em questão, e por um grupo de dez professores lotados em diversas escolas da REME, que se dispuseram ao trabalho intelectual.

Diferentemente da proposta anterior, a Sequência Didática (2000) é um documento único que contempla todos os componentes curriculares inclusive a Educação Física. Esse componente era dividido em dois seguimentos: no que se refere à educação infantil era denominado Movimento e ao ensino fundamental Educação Física.

Essa proposta era subsidiada pelos Parâmetros Curriculares Nacionais (PCNs, 1988) para a disciplina de Educação Física e deveria ser um referencial curricular onde o professor tivesse a possibilidade de buscar outras fontes teóricas. Porém, passa a ser utilizado como um currículo mínimo. Desse modo, a Sequência Didática (2000) organizada em Eixos Temáticos, induzia o professor a planejar suas aulas tendo apenas esse documento como aporte teórico.

Essa organização do currículo seguiu as diretrizes dos modelos de organização curricular da década de 1990 que tinha como característica o esvaziamento dos conteúdos disciplinares dando destaque aos chamados temas transversais.

A Sequência Didática (2000) respaldava uma ação docente tecnicista que não propiciava uma reflexão sobre os princípios político-pedagógicos. $\mathrm{O}$ documento em questão não explicita quais os fundamentos teóricos que sustentava sua escrita. Desta forma, ele é a materialização da política de aprendizagem para os alunos da educação básica que se baseia na performance do discurso sobre um mundo do trabalho no qual o trabalhador deve ser valorizado e capaz de aprender rapidamente, de trabalhar em conjunto com outras pessoas, de ter criatividade, e estar sempre preparado para compreender a instabilidade do mercado de trabalho.

Nessa mesma lógica a Sequência Didática (2000) passou por uma reformulação sendo publicada em único volume com o título de Diretrizes Curriculares do Ensino Fundamental $1^{\text {a }}$ a $8^{\text {a }}$ séries (CAMPO GRANDE, 2003), contemplando todos os componentes curriculares. Foi elaborada pelos técnicos da SEMED, lotados na Divisão de Políticas e Programas para o Ensino Fundamental, que integrava o Departamento de Desenvolvimento de Educação. Igualmente aos outros documentos, a participação docente foi mínima, no caso da Educação Física contou somente com sete professores.

Constatamos nos referenciais na área da Educação Física a perspectiva de um componente curricular que tem como objetivo o desenvolvimento unicamente da aptidão física. Nessas propostas curriculares, observamos a primazia dos elementos técnicos e táticos de esportes como vôlei, basquete, futebol, atletismo, entendidos como conteúdos curriculares predominantes nessa disciplina, em detrimento de outros da cultura corporal, também historicamente acumulado pela humanidade.

Tal fato contribui para a manutenção do poder hegemônico, na medida em que aliena o aluno de sua condição de sujeito histórico, capaz de transformar sua realidade. A alienação ocorre em razão das concepções individualistas, fundadas no pensamento liberal de produtividade e competitividade, que permeiam o ideário da Educação Física escolar, de forma a transmitir acriticamente os conteúdos historicamente acumulados.

Esse quadro expressa, portanto, uma concepção liberal de educação, que, ao utilizar os conhecimentos de sustentação da Educação Física escolar, a exemplo da fisiologia, da filosofia, da psicologia e da biologia, objetiva formar o homem forte, ágil, apto, empreendedor, com capacidade de inserir-se em uma sociedade competitiva de livre concorrência.

Contrapondo ao quadro anteriormente exposto, foi necessária a elaboração de um novo texto para a Educação Física, em que a execução de exercícios físicos padronizados 
desse lugar a uma formação humana em amplas dimensões, onde professor e aluno tomassem consciência sobre seus corpos, não apenas no sentido biológico, mas principalmente em relação ao meio social em que vivem.

Dessa forma, a equipe da SEMED com a participação de cerca de $5 \%$ do quadro efetivo de professores da REME elaborou um texto embasado nas discussões do autor Eleonor Kunz (2003) que defende a concepção Crítico-Emancipatória, anteriormente abordada neste artigo, por compreender que esta oferece suporte teórico-metodológico para o conteúdo Esporte, a partir de uma visão crítica.

O referido texto está inserido no Referencial Curricular (CAMPO GRANDE, 2008), documento ainda em vigência na REME. A Educação Física faz parte de dois dos quatro volumes em que o documento em questão está organizado. São eles: do $1^{\circ}$ e $2^{\circ}$ ano do Ensino Fundamental (Alfabetização, Língua Portuguesa, Educação Física, História, Geografia, Ensino Religioso, Matemática e Ciências) e $3^{\circ}$ ao $9^{\circ}$ ano do Ensino Fundamental (Língua Portuguesa, Língua Estrangeira, Artes e Educação Física).

A escolha pela concepção Crítico-Emancipatória, segundo os técnicos da equipe de Educação Física da SEMED daria oportunidade para ampliar as discussões sobre o esporte, porém de forma pedagógica, bem como levaria o docente a refletir sobre uma prática emancipatória, em que o sujeito pense e aja de forma que desenvolva uma consciência crítica, a autoreflexão, na tentativa de sobreviver em uma sociedade individualista, desenvolvendo processos autônomos, e com isso, contribuindo para sua emancipação ${ }^{7}$.

Nesse sentido o professor de Educação Física na escola torna-se responsável em possibilitar ao aluno, por meio das suas aulas, a compreensão da estrutura autoritária dos processos institucionalizados da sociedade seja, na escola, nas mídias. Uma estrutura que forma as convicções, os interesses e os desejos de quem dela faz parte.

Todavia algumas ações por parte da SEMED não deixaram claras o que seus técnicos compreendiam sobre emancipação. Um exemplo disso foi a supressão do conteúdo "Lutas" do Referencial Curricular (2008), fazendo com que assumisse uma posição contrária ao propósito da emancipação proposto nesse documento.

A concepção Crítico-Emancipatória é alvo de análises comprobatórias que afirmam que o conceito de emancipação está posto de forma limitada principalmente no que se refere ao caráter crítico que essa abordagem expõe sobre os esportes. Segundo Taffarel e Morschbacher, (2013, p. 57) "[...] não se entende que a Educação Física apresente apenas problemas com relação às práticas esportivas". Mesmo conhecendo tais ponderações, por que a SEMED insistiu em elaborar o currículo de Educação Física a partir desses pressupostos teóricos?

Cabe esclarecer que consideramos a obra de Kunz (2003) fundamental para o processo evolutivo da Educação Física no contexto histórico brasileiro. A abordagem do autor (2003) contribui de maneira essencial para o trabalho docente "[...] pondo em xeque os estereótipos que o esporte criou, assim como a visão do alto rendimento que o sistema implantou nessas práticas" (TAFFAREL, MORSCHBACHER, 2013, p. 47). Porém, essa crítica não é suficiente para sustentar o trabalho pedagógico no que se refere ao conhecimento da cultura corporal.

Destacamos que a emancipação humana não se dará se não houver uma ruptura com o atual modelo de sociedade.

A emancipação humana, ou seja, uma forma de sociabilidade na qual os homens sejam efetivamente livres, supõe a erradicação do capital e de todas as suas categorias. Sem esta erradicação é impossível a constituição de uma autêntica comunidade humana. E esta erradicação não significa, de modo algum, o aperfeiçoamento da cidadania, mas, ao contrário, a sua 
mais completa superação. Como diz Marx, nas Glosas Críticas, há uma distância infinita entre o cidadão e o homem, assim como entre a vida política e a vida humana (TONET, 2005, s/p).

Portanto, para que ocorra a emancipação como preconiza o Referencial Curricular (2008) em vigência da REME, a SEMED deve elaborar um projeto que possibilite ao aluno interpretar e intervir na realidade, onde o conhecimento historicamente construído supere a visão reducionista entre a biologia e a psicologia (muito comum no trato com a Educação Física), e passe a compreender que o conteúdo da Educação Física deve ser tratado no campo da cultura corporal.

\section{À guisa de conclusão}

Os currículos de Educação Física apresentados pela rede municipal pública de ensino de Campo Grande/MS, como observamos no texto, sofreram reformulações ao longo dos séculos XX e XXI, de forma a atender aos interesses políticos e econômicos dos grupos que se encontravam a frente a administração pública.

A Educação Física, ao trazer diferentes ideologias em determinados momentos históricos, não pode ser considerada uma prática politicamente neutra, pois revela um posicionamento a favor ou contrário à manutenção da ordem vigente, expressando assim, que tipo de formação se oferece aos alunos da educação básica.

Assim, consideramos este texto como um convite para que os docentes, e, neste caso específico, os de Educação Física na educação básica percebam as ideologias presentes no currículo, além de observarem com atenção e responsabilidade quais conhecimentos devem ser ensinados, com vistas a possibilitar ao aluno tornar-se um sujeito crítico que compreenda todas as relações que existem na sociedade, além de perceber as intencionalidades por trás de cada conhecimento selecionado no currículo. Com essa compressão o professor tem autonomia para elaborar seu plano de trabalho associado à realidade e às necessidades de seus alunos. 
Referências:

BRASIL. Parâmetros Curriculares Nacionais: Educação Física/ Ministério da Educação. Secretaria da Educação Fundamental. Brasília, 1998. Disponível em:

<http://portal.mec.gov.br/seb/arquivos/pdf/livro07.pdf.> Acesso em 17 de mar. de 2016.

República Federativa do. Lei n. 9.394, 20.12.1996. Estabelece as diretrizes e bases da educação nacional. Disponível em:

<http://www.planalto.gov.br/ccivil_03/leis/19394.htm.> Acesso em 17 de mar. de 2016.

BRASIL. República Federativa do. Lei no 10.328, 12.12.2001. Disponível em:

<http://www.planalto.gov.br/ccivil_03/leis/leis_2001/110328.htm>. Acesso em 17 de jan. de 2015. Acesso em 17 de mar. de 2016.

República Federativa do. Lei no 10.793, 01.12.2013. Disponível em:

<http://www.planalto.gov.br/ccivil_03/leis/2003/110.793.htm.> Acesso em 17 de mar. de 2016.

CAMPO GRANDE. Secretaria Municipal de Educação. Alternativas Curriculares. Campo Grande: Prefeitura Municipal de Campo Grande, 1990.

2000.

Sequencia didática. Campo Grande: Prefeitura Municipal de Campo Grande,

. Diretrizes curriculares do ensino fundamental. Campo Grande: Prefeitura Municipal, 2003.

. Referencial curricular da Rede Municipal de Ensino do $1^{\circ}$ ao $9^{\circ}$ ano. Campo

Grande: Prefeitura Municipal, 2008

CASTELLANI FILHO. L. Projeto reorganização da trajetória escolar no ensino fundamental: uma proposta pedagógica para a educação física. Revista da EDUCAÇÃO FÍSICA/UEM 8(1): 11-19,1997. Disponível em:

<http://periodicos.uem.br/ojs/index.php/RevEducFis/article/viewFile/3867/2693>. Acesso em 24 de mar. de 2016.

CAPARROZ, Francisco Eduardo. Entre a educação física na escola e a educação física da escola: a educação física como componente curricular. Campinas, SP. Autores Associados, 2007.

DAOLIO, J. Educação Física Brasileira: autores e atores da década de 1980.Campinas, SP: Papirus, 1998.

DARIDO, S. C.; RANGEL, I. C. A. Educação Física na Escola: Implicações para a prática pedagógica. Rio de Janeiro: Guanabara Koogan, 2005. 
Os conteúdos da Educação Física escolar: influências, tendências, dificuldades e possibilidades. Perspectivas em Educação Física Escolar, Niterói, v. 2, n. 1 (suplemento), 2001. Disponível em: <http://pt.scribd.com/doc/70073429/Os-ConteudosDa-Educacao-Fisica-Escolar-Influencias-Tendencias-Dificuldades-ePossibilidades\#scribd.> Acesso em: 24 de mar. de 2016.

GONÇALVES, M. A. S. Sentir, pensar, agir: corporeidade e educação. Campinas, SP: Papirus, 1994.

GOODSON, I. Currículo: teoria e história. 9. ed. Petrópolis, RJ: Vozes, 2010.

KUNZ, E. Transformação didático-pedagógica do Esporte. Ijuí: Unijuí, 2003.

NEVES, L. M. W e SANT'ANNA, R. Introdução: Gramsci, o Estado Educador e a nova pedagogia da hegemonia. In: NEVES. L. M. W. (Org.) A nova pedagogia da hegemonia - estratégias do capital para educar o consenso. São Paulo: Xamã, 2005.

NORONHA, Olinda Maria. Políticas neoliberais, conhecimento e educação. Campinas: Alínea, 2002.

OLIVEIRA. Francisco. O Surgimento do antivalor. Novos Estudos Cebrap, São Paulo, n.22, p. 8-18, 1988.

POCHMANN, Marcio. O Emprego na Globalização: a nova divisão do trabalho e os caminhos que o Brasil escolheu. Boitempo: São Paulo, 2001.

SAVIANI. D. Pedagogia histórico-crítica: primeiras aproximações. Campinas, SP: Autores Associados, 2011.

SILVA, F. de C. T. Possibilidades e limites no/do estudo comparado de documentos curriculares: a construção da história curricular no campo da educação especial (1979 e 1999). Anais - VI Congresso Brasileiro da História da Educação 2011. Disponível em:<http://www.sbhe.org.br/novo/congressos/cbhe6/anais_vi_cbhe/conteudo/res/trab_100 0.htm.> Acesso em: 15 de mar. de 2016.

SOARES, C. L. et al. Metodologia do ensino da Educação Física. São Paulo: Cortez, 1992.

TAFFAREL C. Z., MORSCHBACHER, M. Crítica A Teoria Crítico-Emancipatória: Um Diálogo Com Elenor Kunz A Partir Do Conceito De Emancipação Humana. Corpus et Scientia v. 9, n. 1, p. 45-64, Rio de Janeiro 2013. Disponível em: http://apl.unisuam.edu.br/revistas/index.php/corpusetscientia/article/view/253. Acesso em: 23 fev. 2016.

TONET, I. Cidadania ou Emancipação Humana. Revista Espaço Acadêmico, Maringá, n. 44, jan. 2005. Disponível em: <http://www.espacoacademico.com.br/044/44ctonet.htm>. Acesso em: 10 de abril de 2016.

ZIBAS, Dagmar. A reforma do ensino médio nos anos de 1990: o parto da montanha e as novas perspectivas. Revista Brasileira de Educação, Rio de Janeiro, n. 28, 2005. 
Disponível em: http://www.scielo.br/scielo.php?script=sci_arttext\&pid=S141324782005000100003\&lng=pt\&nrm=iso>. Acesso em: 10 abril de 2016.

\title{
Notas
}

\begin{abstract}
${ }^{1}$ De acordo com Silva (2011, p. 1) esses documentos são "[...] as publicações que orientam os processos de escolarização e escolaridade em âmbito nacional, regional e local, periodicamente, em intervalos regulares e irregulares, publicadas pelo Ministério da Educação e/ou Secretarias de Estado e Municipais da Educação". Optamos por utilizar os termos documentos curriculares, propostas curriculares como sinônimos neste texto, para nos referirmos aos documentos elaborados pela Secretaria Municipal de Campo Grande (SEMED).

${ }^{2}$ Optamos por utilizar os termos propostas curriculares e documentos curriculares como sinônimos neste texto, para nos referirmos aos documentos elaborados pela Secretaria Municipal de Educação (SEMED) de Campo Grande/MS.

${ }^{3}$ Os anos de 1980 aparecem como o nascimento de concepções e práticas libertadoras, transformadoras na perspectiva de desenvolver uma Educação Física voltada para o humano e não mais para as necessidades do capital. (CAPARROZ, 2007).

4 "Toda a discussão realizada no campo da pedagogia sobre o caráter reprodutor da escola e sobre as possibilidades de sua contribuição para uma transformação radical da sociedade capitalista foi absorvida pela EF. A década de 1980 foi fortemente marcada por essa influência, constituindo-se aos poucos uma corrente que inicialmente foi chamada de revolucionária, mas que também foi denominada de crítica e progressista." (BRACHT, 1999, p. 78).

5“A 'cultura corporal' é uma parte do homem. É configurada por um acervo de conhecimento, socialmente construído e historicamente determinado, a partir de atividades que materializam as relações múltiplas entre experiências ideológicas, políticas, filosóficas e sociais e os sentidos lúdicos, estéticos, artísticos, agonistas, competitivos ou outros, relacionados à realidade, às necessidades e as motivações do homem. A Educação Física estuda o conteúdo da cultura corporal com o objetivo fundamental de explicar criticamente a especificidade histórica e cultural dessas práticas e participar de forma criativa, individual e coletiva, na construção de uma cultura popular progressiva, superadora da cultura de classes dominantes."(SOARES et al., 2009, p. 127-128, grifo dos autores).

${ }^{6}$ Conforme o Parecer CNE/CEB No: 22/2005 a denominação de Educação Artística é substituída por Ensino da Arte.

${ }^{7}$ Para Kunz (1994, p. 33) emancipação é o "[...] processo de libertar o jovem das condições que limitam o uso da razão crítica e com isso todo o seu agir social, cultural e esportivo, que se desenvolve pela educação."
\end{abstract}

Recebido: abril/16 Aprovado: dezembro/16 